\title{
FLUENCE, DOSIMETRY, AND STEEL-DPA RATES IN EBR-II*
}

D. Meneghetti and D. A. Kucera

$\operatorname{cosis}-\sin 0.02--5$

DEQS 015005
Argonne National Laboratory

Argonne, Illinois 60439, U.S.A.
Submitted for Presentation

at the

Fifth ASTM-EURATOM Symposium on Reactor Dosimetry

September 24-28, 1984

Geesthacht (near Hamburg)

Federal Republic of Germany

DISCLAIMER

This report was prepared as an account of work sponsored by an agency of the United States Government. Neither the United States Government nor any agency thereof, nor any of their employees, makes any warranty, express or implied, or assumes any legal liability or risponsibility for the accuracy, completeness, or usefulness of any information, apparatus, product, or process disclosed, or represents that its use would not infringe privately owned rights. Reference herein to any specific commercial product, process, or service by trade name, trademark, manufacturer, or otherwise does not necessarily constitute or imply its endorsement, recommendation, or favoring by the United States Government or any agency thereof. The views and opinions of authors expressed herein do not necessarily state or reflect those of the United States Government or any agency thereof.

*Work supported by the $\mathrm{L}$. S. Department of Energy under contract W-31-109-Eng-38. 


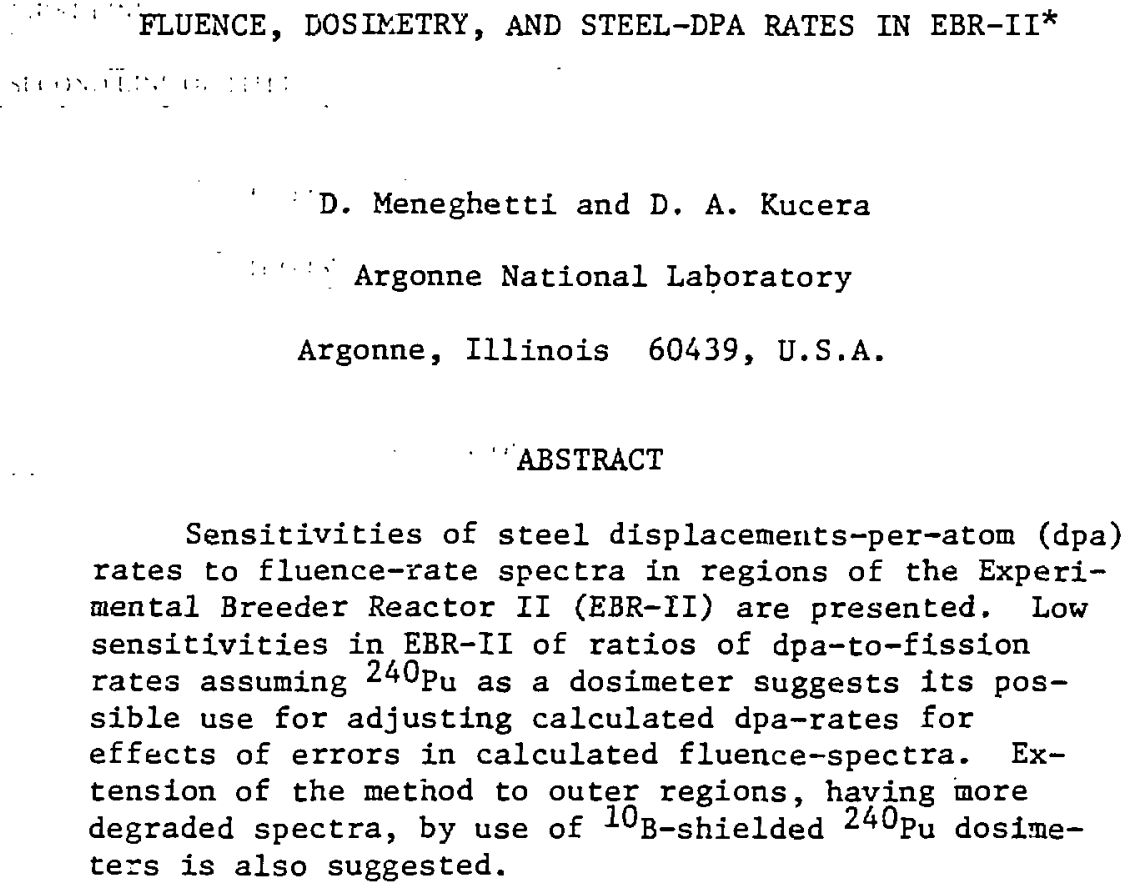

INTRODUCTION

Calculated values of displacements-per-atom (dpa) rates for stainless steel in a reactor environment are useful both for determining correlations between observed volumetric expansions and exposures and for predicting volumetric expansions with exposures. If the values for the displacement cross section are correct, the accuracy of a calculated dpa rate is dependent upon the accuracy of the calculated neutron-flux spectrum at the location.

Neutron spectra at locations in a representative current configuration of the Experimental Breeder Reactor-II (EBR-II) [1, 2]

*Work supported by the U. S. Department of Energy under contract W-31-109-Eng-38. 


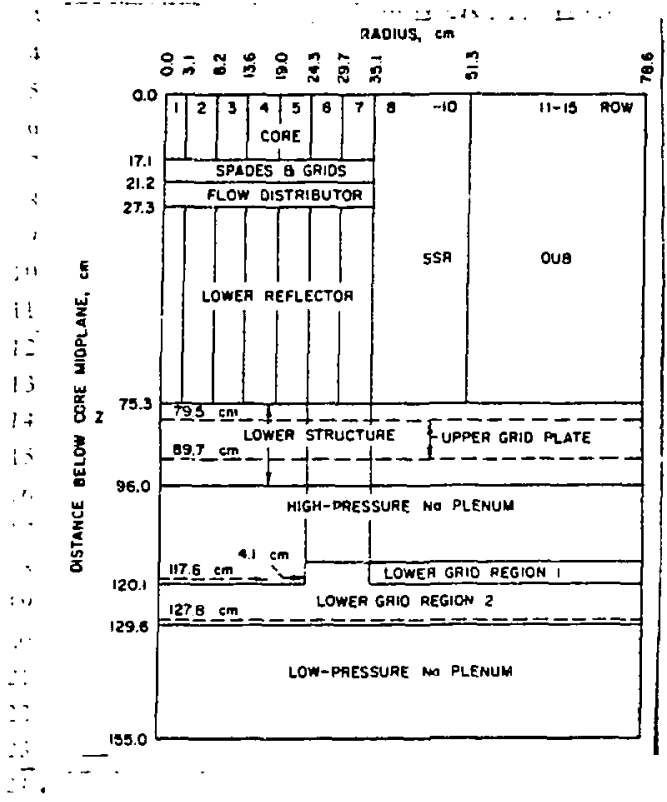

were calculated using the halfheight geometry description shown in Figure 1. Figure 2 shows the calculated flux spectra, in units of neutron fluence per unit lethargy per megawatt-day-thermal of reactor operations, at center of core and at a midline axial 10cation near the middle of the subassembly-supporting gridassembly region. These figures also show the multigroup values of the displacement cross sections of stainless steel used to obtain the shaded regions representing the group contributions to the total dpa-rates. The displacement cross sections are based on reference [3].

Fig. 1. Half-height Calculational Diagram.

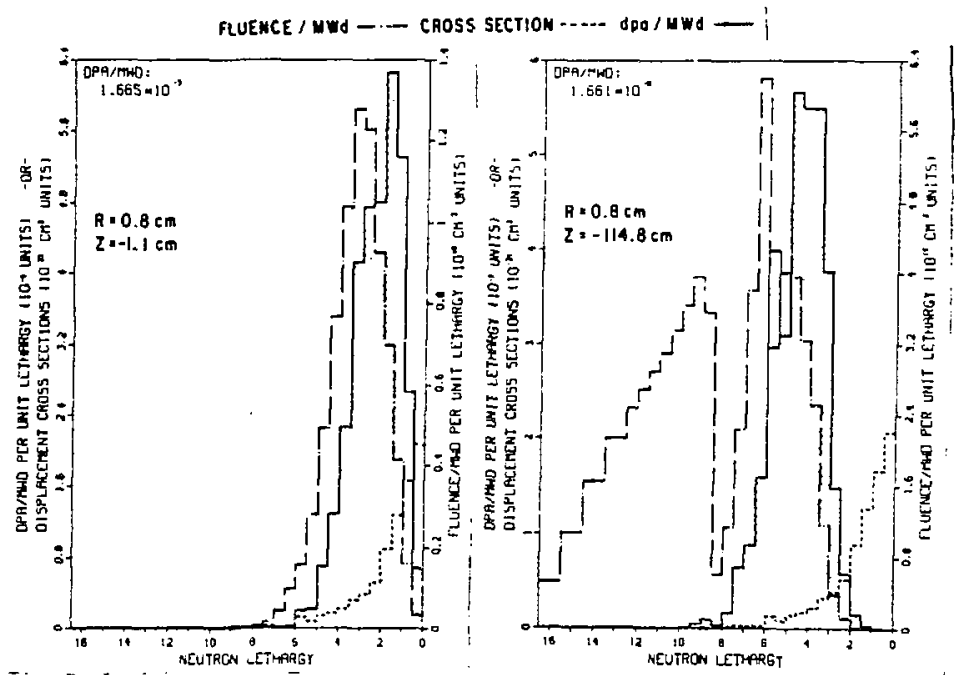

Fig. 2. Lethargy Dependence of Fluence and of Steel dpa Rates at Two Locations. 


\section{SPECTRAL-SHAPE MODIFICATIONS}

The sensttivities of dpa rates to neutron spectra uncertainties were studied by modifying the calculated flux spectra in four different ways. The modifications simulate "real" spectra for comparisons with calculated "errored" spectra. (It should not be construed that any of these "real" spectra is in fact the actual spectra and that the calculated spectra are incorrect. These terminologies are soleily for these sensitivity analyses.) The four spectral modifications are: group soften, group harden, s'kew soften, and skew harden. The group soften and group harden modifications approximate shifts in calculated multigroup spectra by one-quarter lethargy width toward smaller energies and larger energies. The skew soften modffication approximates a $6 \%$ decrease of the calculated multigroup spectra per unit decrease of lethargy from a maximum of $16.5(0.68 \mathrm{eV})$. The skew harden modification approximates a $6 \%$ decrease of the calculated multigroup spectra per unit increase of lethargy from zero (10 MeV). For the modified spectra the total fluence rates were normalized to equal the total fluence rates of the corresponding calculated spectra.

At the central location the calculated dpa-rate differs by about $+16 \%,-16 \%,+40 \%$, and $-6 \%$ from the respective modifiedspectra dpa-rates. At the grid-assembly location the calculated dpa-rate differs by about $+14 \%,-18 \%,+91 \%$, and $-35 \%$ from the respective modified-spectra dpa-rates.

Relative spectral shapes of the skew type modifications together with the calculated spectra, here all normalized to unity for comparisons, are shown in Figure 3 for the central and for the grid-assembly locations.

\section{RATIOS OF DPA RATES TO FISSION RATES}

Calculations were made to determine the possibility of reducing errors in calculated dpa-rates in EBR-II by multiplying simulated-measured fission rates by ratios of calculated dpa rates to calculated fission rates. The isotopes whose fission reactions were scoped are ${ }^{232} \mathrm{Th}, 234 \mathrm{U}, 236_{\mathrm{U}},{ }^{23} 8_{\mathrm{U}},{ }^{23} 7_{\mathrm{Np}},{ }^{240} \mathrm{Pu}$, and ${ }^{242} \mathrm{Pu}$. Ratios based on the ${ }^{240} \mathrm{Pu}$ fission reaction were the least sensitive to simulated-variations of spectral shapes in core, radial reflector and blanket, and in axtal reflector regions within about $30 \mathrm{~cm}$ of the core axial-interfaces. Comparison of the relative shapes of the steel displacement cross sections and of the fission cross sections of $240 \mathrm{Pu}$ are shown in Fj.gure 4 . The displacement-to-fission ratios, $D / F$, at various axial and radial locations are shown ir. the top set of curves of Figure 5 for the calculated spectral-shapes and for the four modified spectral-shapes. 


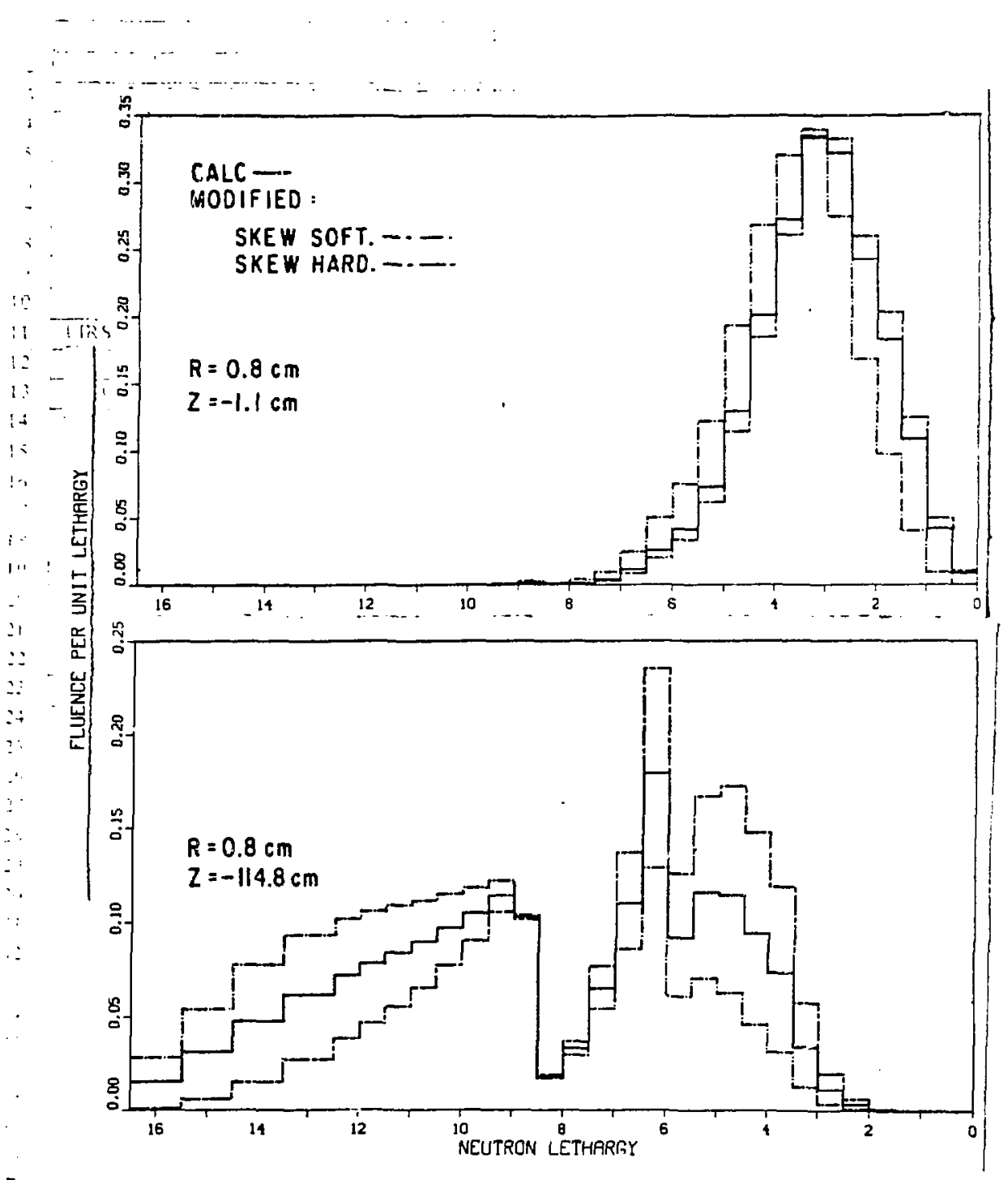

F1g. 3. Calculated and Modified Spectral Shapes at Two Locations.

The ratios from the unmodified spectra to those from the modifled spectra in core, radial-reflector, radicl-blanket, and at axlal-reflector regions within about $30 \mathrm{~cm}$ of core bottom are such that the calculated (unmodified) ratios together with simulated measured fission rates correct the calculated (unmodified) dpa rates for stainless steel to well within $10 \%$ of these simulated "real" values in core locations and within about $15 \%$ in these 
out-of-core locations." '(Because the dpa-to-fission ratios are dependent only on spectral shapes, these same percentages are retained irrespective of the magnitude factors by which the unmodified spectra differ.) With increasing distance into the lower regions of steel and sodium the errors become prohibitively large for some spectral modifications because of the contributions of the sub-threshold fissions.

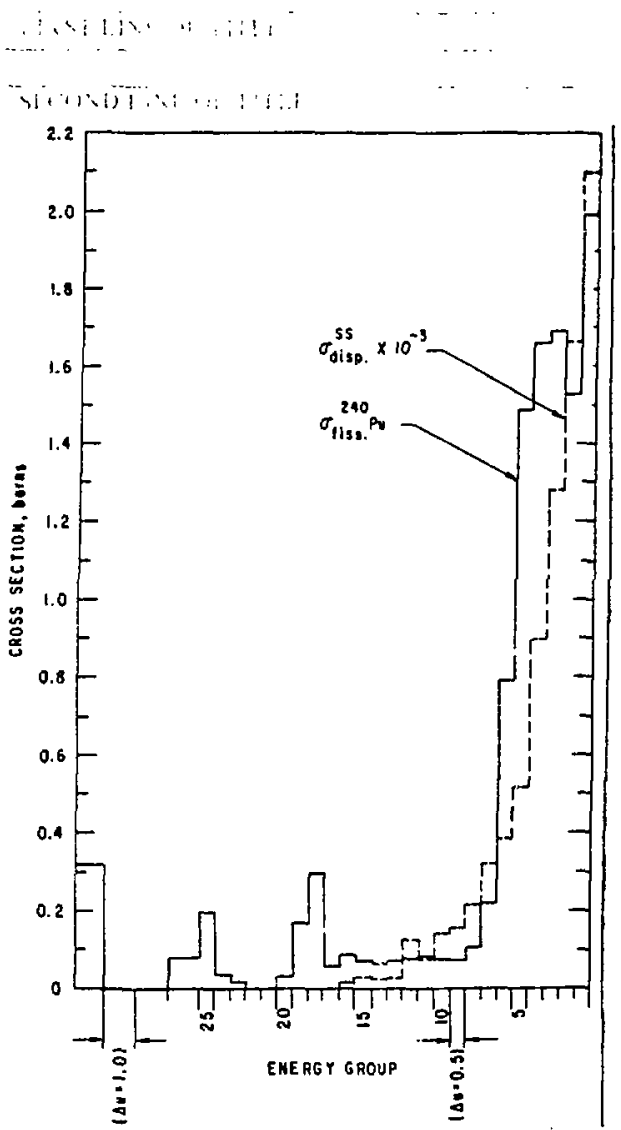

Fig. 4. ${ }^{240} \mathrm{Pu}$ Fission Cross

Sections (ENDF/B-V) Compared with Steel Displacement Cross Sections (based on [3]).
To ascertain whether consideration of removal of subthreshold fission components from measurements would be helpful, fission-truncated zatios, $D / F$ trun, were calculated assuming no sub-threshold fissions below $20.3 \mathrm{keV}$ (corresponding to lethargy 8.5) which is the demarcation between energy multigroups numbers 18 and 19 . (Because of the very small displacement cross section values for the lower energy groups, $18 \rightarrow 29$, non-truncation or truncation of the displacement cross sections result in essentially Identical numerators in these ratios.) These ratios, shown In the middle set of curves in Figure 5, indicate that corrected calculated dpa rates within 15\% should be obtalned also in the deeper out-of-core axial regions, if a method can be devised for estimating the subthreshold fissions of a fission measurement. 


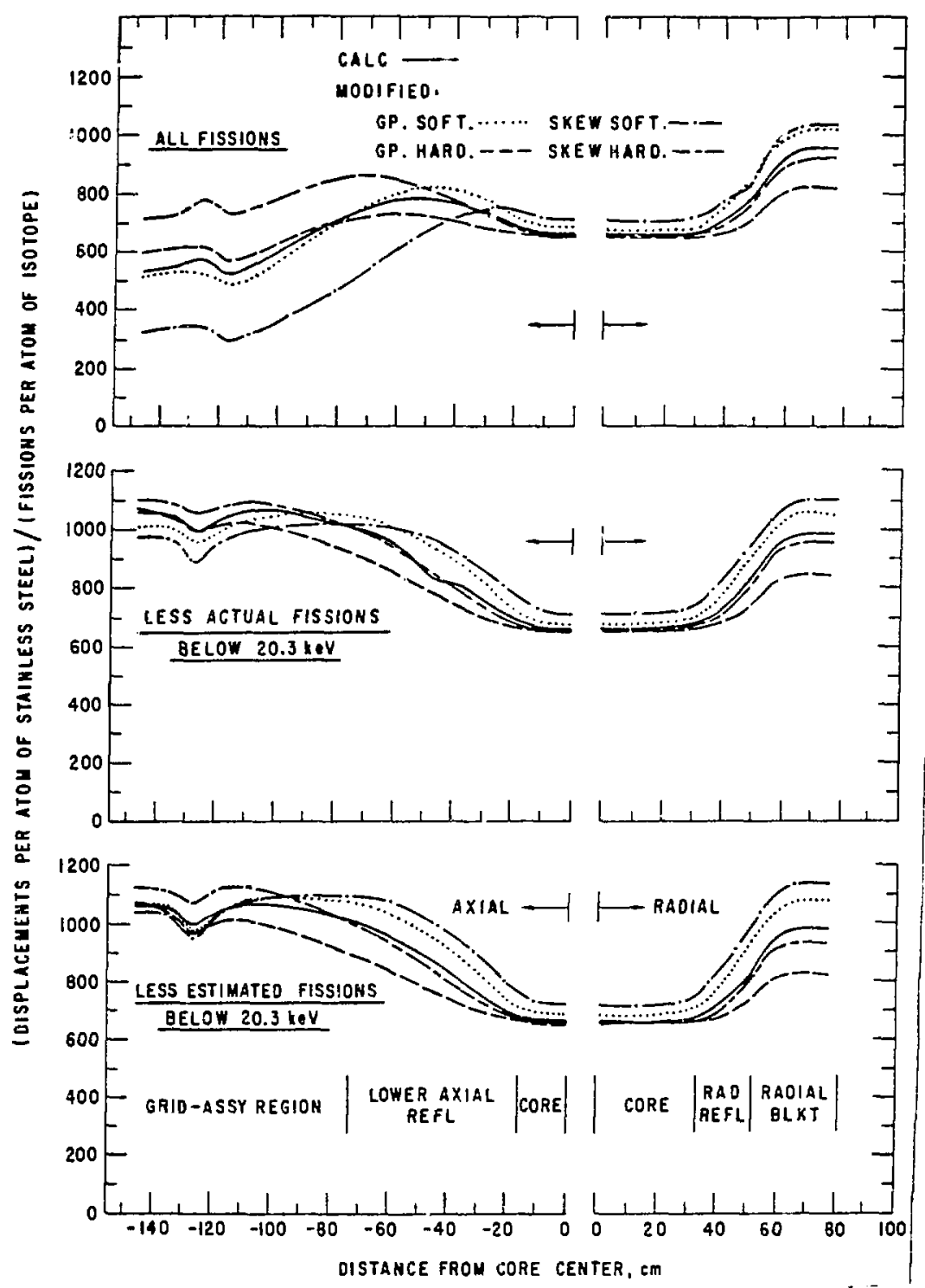

Fig. 5. Spectral Sensitivities of Steel dpa to $240_{\mathrm{P}_{u}}$ Fission with and without Sub-threshold Fission.

\section{ESTIMATING SUB-THRESHOLD FISSIONS}

A possible method for estimating the sub-threshold rate, FSUGt, of a measured fission rate, $M_{0}$, is here very-briefly de- 
scrlbed. The method assumes that the unknown sub-threshold portion of a neutron spectrum can be estimated from the calculated sub-threshold portion of a neutron spectrum, in such regions, by lethargy dejendence of the form

$$
\phi_{\text {est }_{j}}=\phi_{\text {calc }_{j}} A \exp \left[a\left(\bar{u}_{j}-\vec{u}_{18}\right)\right]
$$

for groups $j \geq 18$. The constants, " $A$ " and " $a$ ", for that location, are found by solution of a set of equations using as input values the measured fission rate of the isotope and the measured fission rates of the isotope when shielded by thin-absorbers of $10_{B}$ of two different thicknesses. The $10_{\mathrm{B}}$ absorbers, however, must be thick enough and sufficlently different in thicknesses so that the constants can be determined; but, the absorbers must be thin enough so that the attenuation of the above-threshold fissions are minimal. Minimal means that the reduction of above-threshold fission rate due to a shield is sufficiently small that this above-threshold reduction can be assumed to be that of a spectrum having the above-threshold spectral-shape of the calculated spectrum for purposes of the accounting of the above-threshold reductions in the fission-rate measurements due to the shields. The above-threshold fluence-rate spectrum impinging on the shields (and on the unshielded detector) is for purposes of loss of fissions due to $10_{\mathrm{B}}$ capture assumed to be

$$
\phi_{\text {est }}=\phi_{\text {calc }}\left[\left(M_{0}-F_{\text {est }}^{\text {sub }}\right) / F_{\text {calc }}^{t r u n}\right] \text {, for } j=1+17 \text {, }
$$

where

$$
F_{\text {calc }}^{\text {trun }}=\sum_{j=1}^{17} \sigma_{F_{j} \phi_{\text {calc }}} \text { and } F_{\text {est }}^{\text {sub }}=\sum_{j=18}^{29} \sigma_{F_{j}} \phi_{\text {est }} .
$$

To test this method of estimating the sub-threshold fission rate of a measured fission rate and to simulate its application, simulated-measured values of bare and shlelded fisston rates based on the various modified spectral types were used as measured values and solutions were obtalned using this method. The $10_{B}$ shields were assumed to be of thicknesses $0.05 \mathrm{~cm}$ and $0.10 \mathrm{~cm}$. A comparison of the estimated sub-threshold fissions at varlous axial locations, with the calculated sub-threshold fissions and with the "true" sub-tireshold fissions of the skew-softening spectral modification, is shown in Figure 6 . (The ordinate units in these figures wre given as these quantities divided by the calculated above-threshold fission rate $i . e .$, the calculated truncatedfission rate.) The values of the estimated sub-threshold fissions 


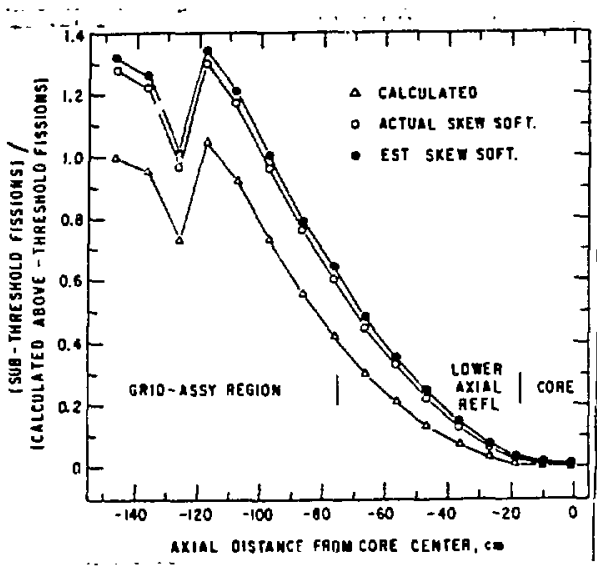

are seen to be considerably closer to those of the corresponding values of the modifiedspectra sub-threshold fissions than to the values of the calculated sub-threshold fissions in those locations having large diffe:ences from the calculated values.

FIg. 6. Relative Values of Sub-' threshold 240Pu Fissions.

The unshielded simulated-measured fission rates based on the varlous spectral-modifications were then reduced by the corresponding estimated values of the sub-threshold fissions (obtained using the above method) to obtain the estimated simulated-measured fission values without sub-threshold fissions. The ratios of the dpa-rates divided by the corresponding values of estimated abovethreshcld fission rates are shown in the lower set of curves in Figure 5. The close similarity between this set of curves with the middle set, iepresenting idealized fission truncation, indicates the possible feasibility of this method for approximation of the truncation and thus enabling tine truncation method to be utilized for correction of calculated dpa rates in such regions of EBR-II if necessary.

\section{REFERENCES}

1. L. J. Koch et al., Proc. 2nd UN Int. Conf. PUAE $\underline{9}$ (1958) 323.

2. F. S. Kirn, "EBR-II as a Fast Reactor Irradiation Facility," Nuclear News (March 1970).

3. D. G. Doran and N. J. Graves, "Displacement Cross Sections and PKA Spectra: Tables and Applications," HEDL-TME 76-70, Hanford Engineering Development Laboratory (1976). 